\title{
Unusual Presentation of Flexor Tendon Sheath Massive Ganglion
}

\section{Saleeb $\mathrm{H}^{*}$ and Kanvinde $\mathrm{R}^{2}$}

${ }^{1}$ Orthopaedic Registrar, Betsi Cadwaladr University Health Board

${ }^{2}$ Consultant Orthopaedic Surgeon, Betsi Cadwaladr University Health Board

${ }^{*}$ Corresponding author: Saleeb H, Orthopaedic Registrar, Betsi Cadwaladr University Health Board, E-mail: mr.hany.saleeb@gmail.com

Citation: Saleeb H, Kanvinde R (2016) Unusual Presentation of Flexor Tendon Sheath Massive Ganglion. J Surg Oper Care 1(1): 105. doi: 10.15744/2455-7617.1.105

Received Date: August 23, 2015 Accepted Date: December 29, 2015 Published Date: January 04, 2016

\begin{abstract}
We report a unusual case of a flexor tendon sheath ganglion in a 78 years old, right hand dominant female presented with right little finger large multiloculated swelling involving the whole volar aspect of the little finger leaving the patient with fears of malignancy, swollen finger with limited mobility and distal tip numbness. Clinical examination revealed large painless multiloculated swelling about $4 \mathrm{~cm} \times 2 \mathrm{~cm} \times 3 \mathrm{~cm}$ with no involvement of neurovascular bundle though patient reported some occasional numbness in the tip of her little finger, as well as positive transillumination, limited mobility due the size of the swelling. The importance of the simple invaluable tools of history taking and focus on clinical examination, simple investigations. A comprehensive knowledge of the regional anatomy together with good preoperative diagnostic technique is essential for their safe excision particularly in those with unusual presentation.
\end{abstract}

\section{Background}

Ganglion cysts affect the hand and wrist; they are frequently seen in patients attending the orthopaedic clinics. Women are more commonly affected than men. These lesions usually arise adjacent to joints or tendons. Dorsal wrist ganglion cysts account for $60-70 \%$ while the volar ones for $18-20 \%$. Although much has been written about this common hand tumor, little attention has been given to flexor tendon sheath ganglions, which are often referred to as volar retinacular cysts or "sesamoid" or "pearl-seed" ganglia. Incidence of volar massive ganglion arising from flexor tendon sheath is uncommon. The etiology of the flexor tendon sheath ganglion is unknown [1-3]. One of the less common sites for the development of ganglion is the flexor tendon sheath of a finger or thumb. Ganglia arising here are usually small and unilocular. They show little tendency to increase in size with the passage of time. Unlike most other ganglia, they are tender-often acutely so-and the degree of disability they produce is out of all proportion to their size [4].

\section{Case Presentation}

78 years old female patient who is right hand dominant with past medical history of Hypothyroidism on oral levothyroxine tablets presented with a swelling on the volar side of her right little finger (Figure 1). Her main concern that she cannot use her finger as a right handed person and she was worried of the rapid reformation of such swelling in the due course of few days. Initially all she had was 1-2 cm swelling on the finger which was aspirated 1 year ago uneventfully. Histology showed a simple ganglion.

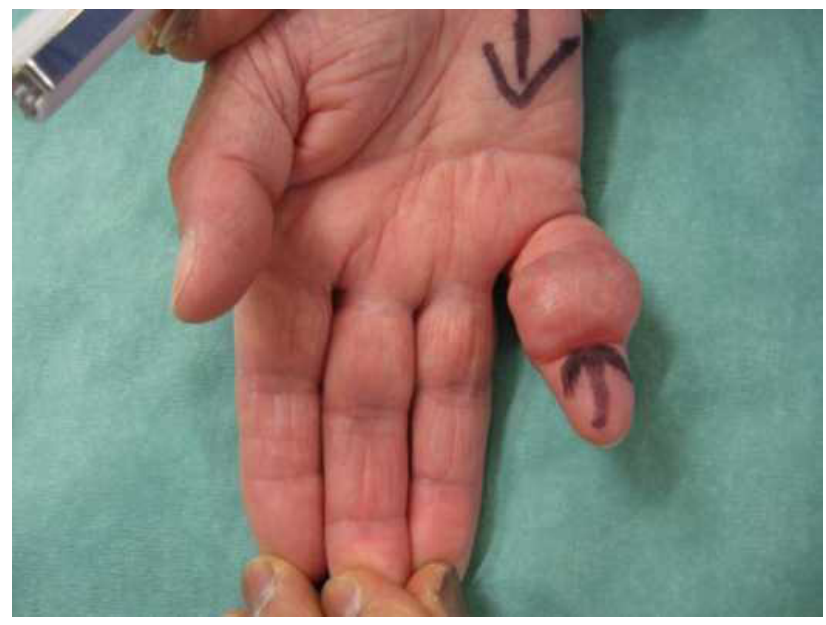

Figure 1: Swelling on the volar side of her right little finger 
Since then she started noticing rapid formation a swelling almost involving the whole finger leaving her with nonfunctional finger with numbness on its tip. Clinical examination revealed large painless multiloculated swelling about $4 \mathrm{~cm} \times 2 \mathrm{~cm} \times 3 \mathrm{~cm}$ with no involvement of neurovascular bundle though patient reported some occasional numbness in the tip of her little finger. The swelling was not mobile with attempts to bend fingertip with limited finger mobility due the size of the swelling especially at PIP joint. Positive transillumination test (Figure 2).

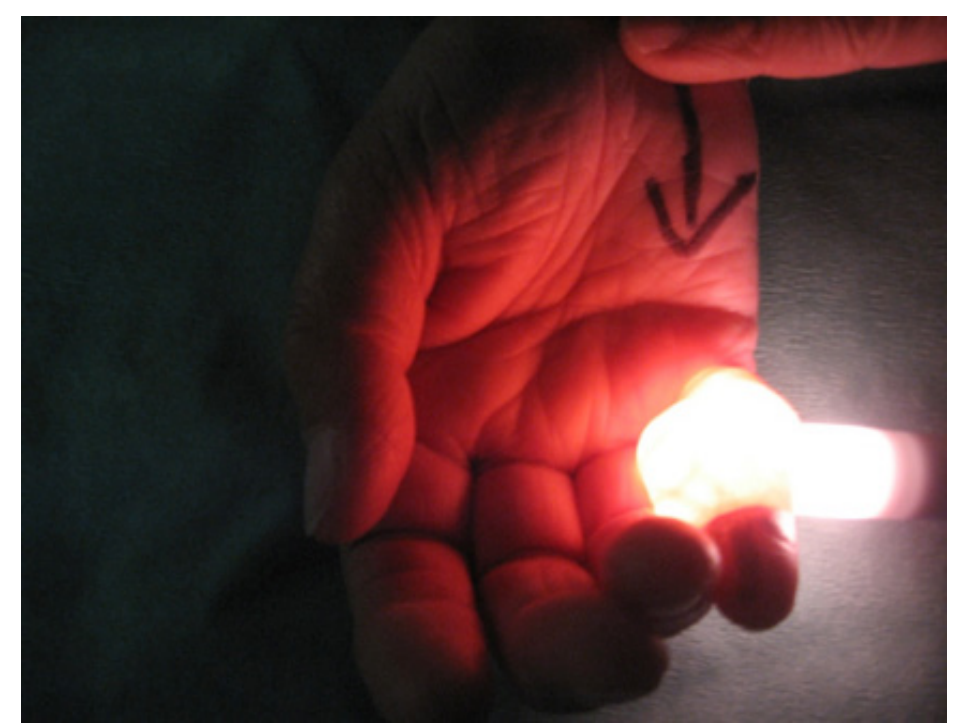

Figure 2: Transillumination test

\section{Investigations}

$\mathrm{X}$ rays did not show any bony abnormalities. Ultrasound scan showed multiloculated swelling related to the tendon.

\section{Differential Diagnosis}

\section{Giant Cell Tumor of the Tendon Sheath}

Giant cell tumors of the tendon sheath are the second most common tumors of the hand, with simple ganglion cysts being the most common. Chassaignac first described these benign soft-tissue masses in 1852, and he overstated their biologic potential in referring to them as cancers of the tendon sheath. Giant cell tumors of the tendon sheath (GCTTS) are uncommon and usually benign lesions that arise from the tendon sheath. It is unclear whether these lesions represent neoplasms or simply reactive masses. It is also known as pigmented villonodular tumor of the tendon sheath (PVNTS) or extra-articular pigmented villonodular tumor of the tendon sheath $[5,6]$. The clinical differential diagnosis may include foreign body granuloma, necrobiotic granuloma, tendinous xanthoma, fibroma of the tendon sheath, infection, ganglion cyst, rheumatoid nodule, epidermoid cyst, lipoma, and a knuckle pad, among other less common entities (Figure 3 and 4). Many of these entities can often be excluded with careful history taking and physical examination $[7,8]$.

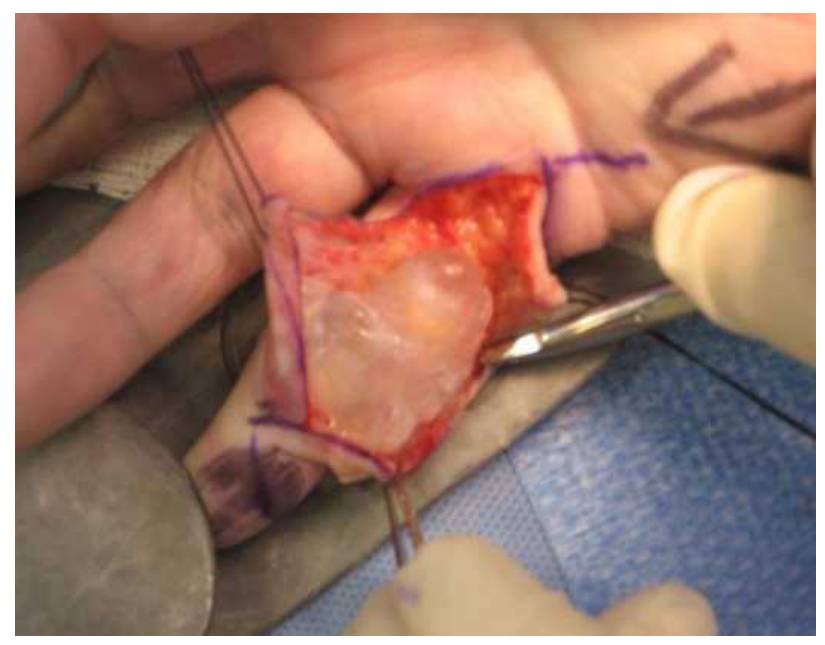

Figure 3: Intraoperative images 1 


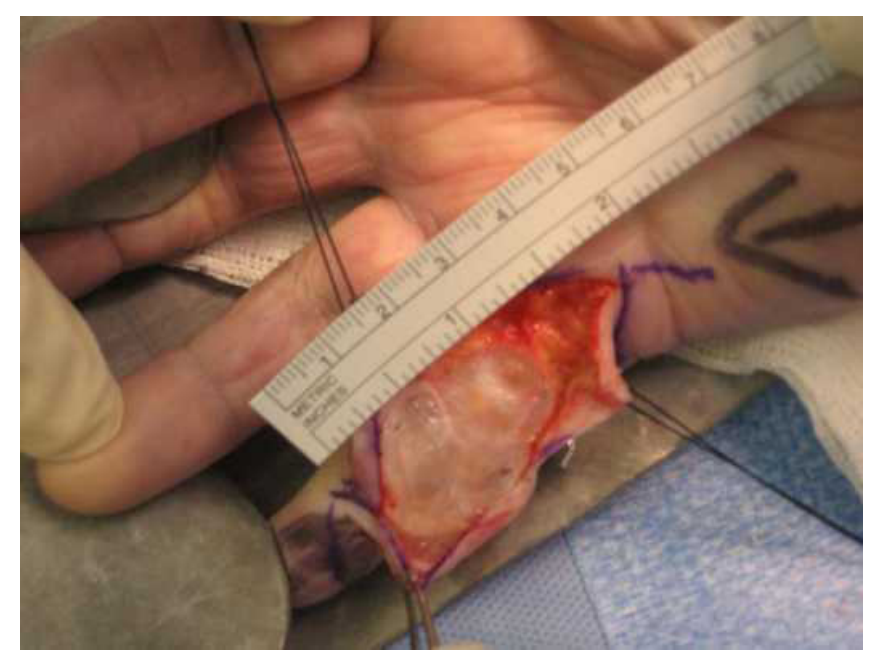

Figure 4: Intraoperative size $4 \mathrm{~cm} \times 3 \mathrm{~cm} \times 2 \mathrm{~cm}$

\section{Treatment}

Though a variety treatment modalities had been advocated for ganglions in general. In our case surgical excision after careful preoperative planning as shown in the figures taking in consideration the skin condition, size of the defect was the best option (Figure 5). Other modalities of treatment as aspiration of the cyst followed by injection usually with steroids was not an option after recurrence.

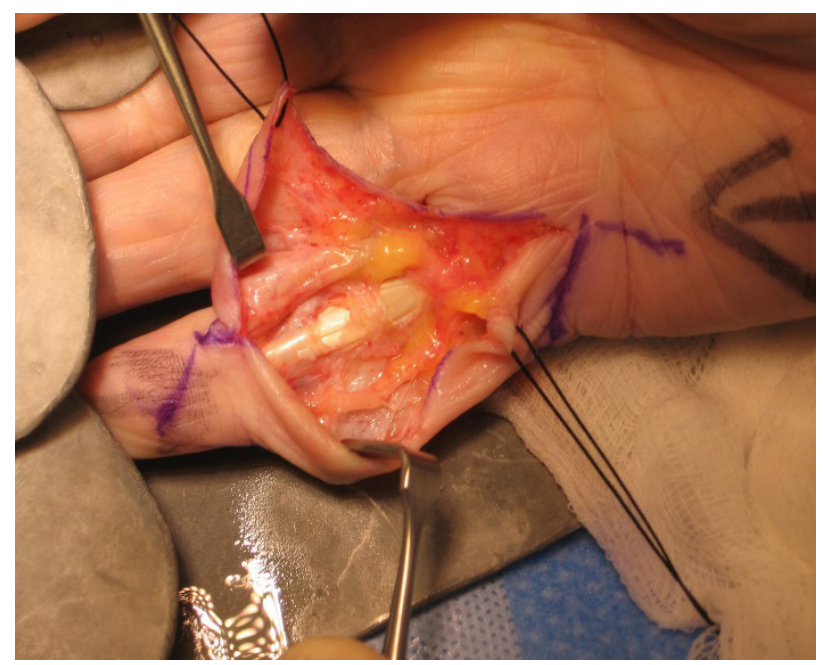

Figure 5: After surgical excision

\section{Outcome and Follow-Up}

Patient postoperatively had functional finger with intact neurovascular bundle.

\section{Discussion}

There are a few reported cases of flexor tendon sheath ganglion reported. Our search showed few reports in the literature on the results of surgery for ganglia of the flexor tendon sheaths of the digits [5,3]. Case reports on massive flexor tendon sheath ganglions were not abundant. Our search showed only one case of a flexor tendon sheath ganglion in a 17-year old female who presented with pain, triggering and a swelling at the base of her right ring finger. Ganglion was measuring only $0.5 \times 0.8 \times 0.4 \mathrm{~cm}$ in size was removed from the A2 pulley area. [9].

\section{Learning Points/Take Home Messages}

Unusual presentations of ganglions may be encountered inspite of the atypical age, size and extension of the swelling. The diagnosis may be established preoperatively by History taking and physical examination and non-expensive investigations as $\mathrm{x}$ rays and ultrasound. Planning the surgical incision in such cases can ensure safe dissection and complete excision. Etiology of ganglions remain not very well understood. The usual size is about $1-2 \mathrm{~cm}$, but some atypical cysts exist. The cyst presents frequently as painless, small soft tissue mass. A comprehensive knowledge of the regional anatomy together with good preoperative diagnostic technique is essential for their safe excision particularly in those with unusual presentation. 


\section{References}

1. Angelides AC (1999) Ganglions of the hand and wrist. Operative hand surgery 2171-83.

2. Carp L, Stout AP (1928) A study of ganglion with special reference to treatment. Surg Gynecol Obstet 46: 460-8.

3. Matthews P (1973) Ganglia of the flexor tendon sheaths of the hand. J Bone Joint Surg 55: 612-7.

4. Herrington JL, Edwards LW (1955) Ganglion cysts arising in unusual locations. Ann Surg 142: 900-3.

5. Finsen V, Håberg Ø, Borchgrevink GE (2013) Surgery for ganglia of the flexor tendon sheath. Orthop Rev 5: e6.

6. Messoudi A, Fnini S, Labsaili N, Ghrib S, Rafai M, et al. (2007) Giant cell tumors of the tendon sheath of the hand: 32 cases. Chir Main 26: 165-9.

7. Sluijmer HC, Becker SJ, Ring DC (2013) Benign upper extremity tumors: factors associated with operative treatment. Hand (N Y) 8: 274-81.

8. Mulkeen D, Chin-Aleong J, Callaghan J, McCann J, Regan PJ (2000) Fibrous histiocytoma of tendon sheath of the hand. Ir Med J 93: $236-9$.

9. Gunaseelan P, Jeremy P, Chua C, Rashdeen F (2015) Ganglion of the Flexor Tendon Sheath at the A2 Pulley. Malay Ortho J 9: 28-9.

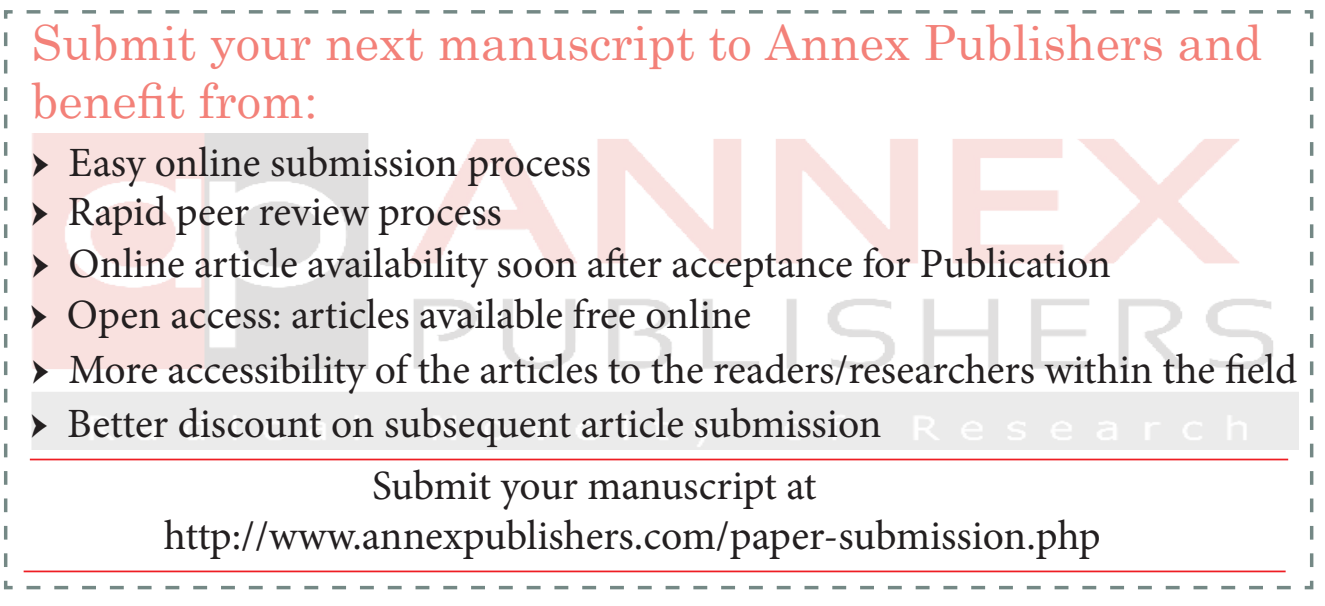

